\title{
Management of acute diverticulitis in Covid 19 times. Our experience.
}

Ana Quiroga-Valcárcel*, Ana Sánchez-Gollarte, Belén Matías-García, Yousef Allaoua-Moussaoui, Fernando Mendoza-Moreno, Lucas Casalduero-García, Diego Córdova-Martín, Manuel Mariano Díez-Alonso, Alberto Guitérrez-Calvo

Department of General and Digestive Surgery, Príncipe de Asturias Teaching Hospital, Alcalá de Henares, Madrid, Spain

*Corresponding Author: Ana Quiroga-Valcárcel, Department of General and Digestive Surgery, Príncipe de Asturias Teaching Hospital, Alcalá de Henares, Madrid, Spain

Received date: 01 February 2021; Accepted date: 02 April 2021; Published date: 06 April 2021

Citation: Quiroga-Valcárcel A, Sánchez-Gollarte A, Allaoua-Moussaoui Y, Mendoza-Moreno F, et al. Management of acute diverticulitis in COVID 19 times. Our experience. J Med Case Rep Case Series 2(4): https://doi.org/10.38207/jmcrcs20210023

Copyright: (C) 2021 Ana Quiroga-Valcárcel. This is an open-access article distributed under the terms of the Creative Commons Attribution License, which permits unrestricted use, distribution, and reproduction in any medium, provided the original author and source are credited.

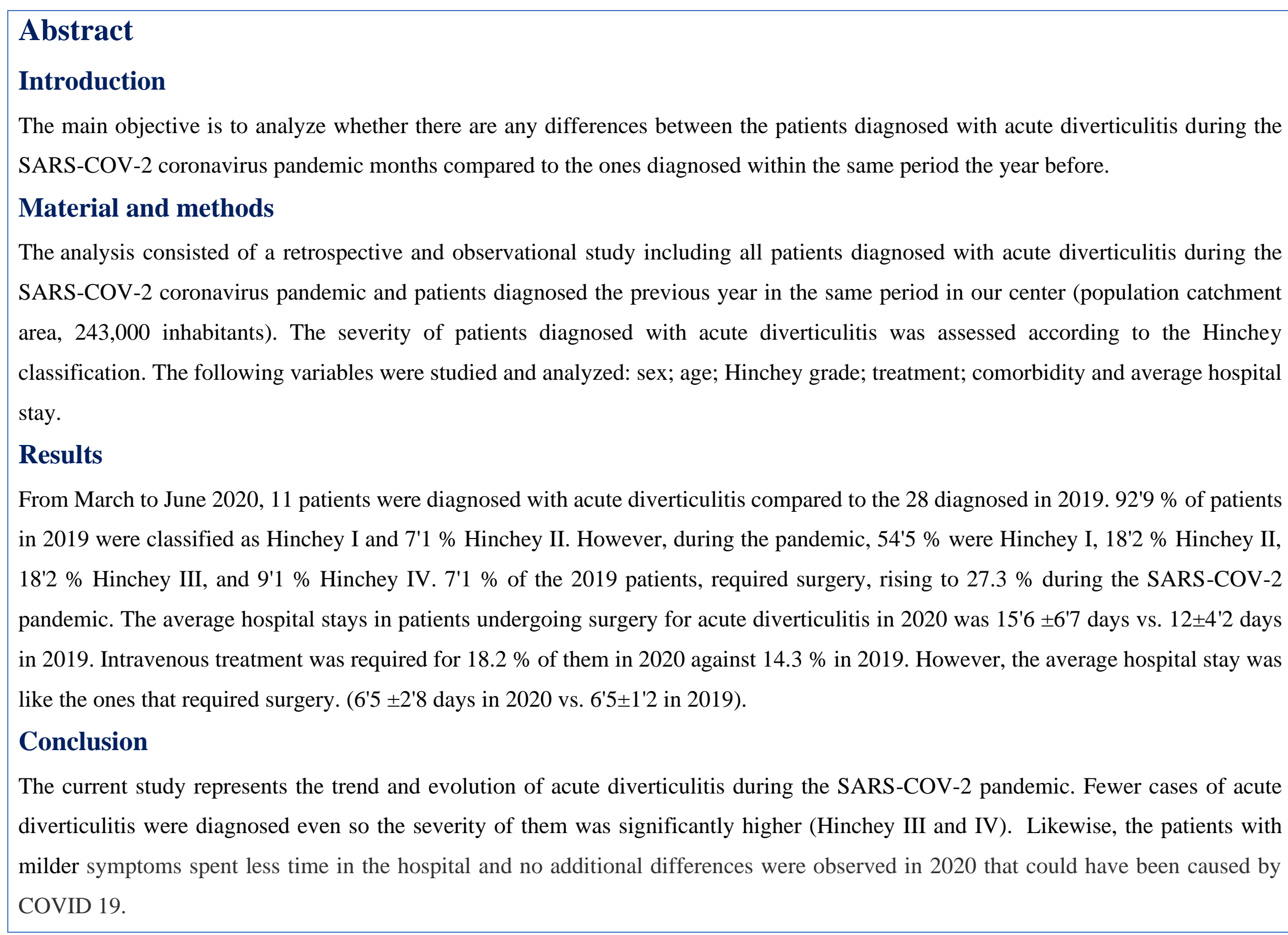

\section{Introduction}

Acute diverticulitis is a disease to be taken care of by the emergency department. It is characterized by left lower quadrant pain, fever, nausea or vomiting, and analytical parameters of infection (leukocytosis, increased C-reactive protein). These symptoms occur because of the inflammation/infection of the bowel wall. It has been a significant increase in the frequency of illness worldwide. There is a current incidence in the USA of approximately 180/100,000 people per year [1,2].
Once there are signs of illness, an abdominal CT with contrast, which is the chosen radiological study, is performed to confirm the assessment. It allows us to differentiate the degree of complication. Up to $10 \%$ of patients will require surgical treatment for complicated diverticulitis [3]. Currently, the modified Hinchey Classification is used to break down the degree of complication to know how to proceed (Table 1) [4]. 


\begin{tabular}{|c|c|c|}
\hline \multicolumn{3}{|c|}{ Modified Hinchey Scale } \\
\hline Grade & Description & Category \\
\hline 0 & $\begin{array}{l}\text { Clinically mild diverticulitis, or diverticula with thickening of the colon wall on } \\
\text { CT scan }\end{array}$ & Not complicated \\
\hline Ia & $\begin{array}{l}\text { Thickening of the colon wall with inflammatory reaction in the pericolic fat } \\
\text { (phlegmon). }\end{array}$ & Not complicated \\
\hline $\mathrm{Ib}$ & Pericolic or mesenteric abscess closed to the primary inflammatory process. & Complicated \\
\hline II & $\begin{array}{l}\text { Intra-abdominal abscess distance from the primary inflammatory process; pelvic } \\
\text { or retroperitoneal abscess. }\end{array}$ & Complicated \\
\hline III & Generalized purulent peritonitis. & Complicated \\
\hline IV & Generalized fecaloid peritonitis. & Complicated \\
\hline
\end{tabular}

Table 1: The treatment will vary accordingly to the degree of involvement. According to the Hinchey classification, the treatment ranges from antibiotherapy on an outpatient basis to major surgery. Surgical treatment can range from percutaneous drainage, laparoscopic drainage to surgical resection (sigmoidectomy and terminal stoma) (Table 2).

\begin{tabular}{|l|l|}
\hline \multicolumn{2}{|c|}{ Treatment according to Hinchey classification } \\
\hline Grade & Type of treatment \\
\hline 0 & $\begin{array}{l}\text { Liquid diet (2-3 days) } \\
\text { Oral antibiotherapy }\end{array}$ \\
\hline Ia & $\begin{array}{l}\text { Liquid diet (2-3 days) } \\
\text { Oral antibiotherapy }\end{array}$ \\
\hline Ib & $\begin{array}{l}\text { If tolerated orally, liquid diet } \\
\text { Oral or i.v. antibiotherapy, according to severity. } \\
\text { If abscess <3 cm, antibiotherapy } \\
\text { If the abscess is large, percutaneous drainage. } \\
\text { Surgical resection if the abscess is not manageable percutaneously. }\end{array}$ \\
\hline II & $\begin{array}{l}\text { Absolute diet } \\
\text { Hospitalization } \\
\text { Intravenous antibiotics } \\
\text { Percutaneous drainage of the abscess } \\
\text { Elective surgical resection }\end{array}$ \\
\hline III & $\begin{array}{l}\text { Absolute diet } \\
\text { Hospitalization } \\
\text { Intravenous antibiotics } \\
\text { Urgent surgery } \\
\text { Absolute diet } \\
\text { Intravenous antibiotics } \\
\text { Urgent surgery }\end{array}$ \\
\hline
\end{tabular}

Table 2: On the other hand, this year 2020 we have experienced a SARS-COV-2 coronavirus pandemic (period between March $14^{\text {th }}$ and June $\left.21^{\text {st }}, 2020\right)$. 
The coronavirus is an RNA+ virus and belongs to the Coronaviridae family. Even though the main cause is a primary respiratory illness, the clinical presentation can range from no symptoms to septic shock and death. The first reported outbreak was in Wuhan, China, in December 2019. By March 2020, about 96,000 cases of coronavirus disease 2019 (COVID-19) and 3300 deaths had been reported [5]. The Community of Madrid was one of the most affected areas in Spain during the months of highest incidence, where Alcalá de Henares belongs to. Up to 250,000 cases and 25,000 deaths occurred between March and June 2020 [6].

The virus has a high spread rate, most commonly between people who are in close contact as well as aerosols. An average incubation period of 5-6 days has been estimated, but it could vary in a range of 1-14 days. [7]. A lot of resources are being currently used to broaden the knowledge of the virus and enhance the diagnostic and treatment methods. So far, treatments with potent antiretrovirals such as remdesivir, or lopinavir/ritonavir, chloroquine have been tried... Without concluding in any successful scientific evidence. Currently, vaccines have already been marketed and are beginning to be dispensed in Spain, but there are still some uncertainties to be resolved such as long-term side effects, or duration of immunity, among others.

\section{Material and methods}

The analysis consisted of a retrospective observational study including all patients diagnosed with acute diverticulitis during the SARS-COV-2 coronavirus pandemic (period from March 14 to June 21, 2020). The comparison was made between patients diagnosed in our center during the same period for both years (population catchment area, 243,000 inhabitants). The technique used to diagnose all the patients were contrast-enhanced abdominopelvic CT. All the patients underwent blood tests on admission and were screened for COVID 19 disease with PCR. The degree of diverticulitis was classified according to the Hinchey classification. The following variables were studied and analyzed: sex; age; Hinchey grade; treatment; morbimortality and mean hospital stay. The data was tabulated in a Microsoft ${ }^{\circledR}$ Office Excel 2007 spreadsheet. The SPSS program was used for the statistical study.

\section{Results}

From March 14 to June 21, 2020, 11 patients were diagnosed with acute diverticulitis compared to the 28 in the same period in 2019. The average age was $65 \pm 5^{\prime} 9$ and $64 \pm 12$ '5 years respectively, presented more frequently in women (71 \% 2020 and $60 \%$ in 2019). 92'9 \% of the patients in 2019 were classified as Hinchey I and 7' $1 \%$ Hinchey II. However, during the pandemic, 54'5\% were Hinchey I, 18'2\% Hinchey II, 18'2 \% Hinchey III, and 9'1\% Hinchey IV. 7'1 \% required surgical treatment in 2019 , rising to $27.3 \%$ during the SARS-COV-2 pandemic. Sigmoidectomy and terminal stoma (Hartmann intervention) was associated with all the surgeries performed in 2020 while more conservative procedures were performed in 2019 such as cavity lavage and drainage were performed, versus a single Hartmann intervention. The average hospital stays in patients surgically intervened for acute diverticulitis in 2020 was $15^{\prime} 6 \pm 6^{\prime} 7$ days versus $12 \pm 4^{\prime} 2$ days in 2019. 18'2 \% were admitted during the pandemic for intravenous treatment versus $14^{\prime} 3 \%$ in 2019 . However, the average hospital stay was similar (6'5 $\pm 2^{\prime} 8$ days in 2020 vs. 6'5 $5 \pm 1^{\prime} 2$ in 2019). Only 1 patient of the 11 diagnosed with diverticulitis in 2020 presented COVID 19 disease without associated morbidity to the initial process. (Table 3.) All patients admitted for acute diverticulitis received enoxaparin at prophylactic doses during their stay. No thrombotic episodes were observed in either COVID-positive patients or in either group.

\begin{tabular}{|l|c|c|}
\hline & COVID patients & NO COVID patients \\
\hline Number of patients with Acude Diverticulitis & 11 & 28 \\
\hline Hinchey I & $54.5 \%$ & $7.1 \%$ \\
\hline Hinchey II & $18.2 \%$ & - \\
\hline Hinchey III & $18.2 \%$ & - \\
\hline Hinchey IV & $9.1 \%$ & $7.1 \%$ \\
\hline Patients who underwent emergency surgery & $27.3 \%$ & $14.3 \%$ \\
\hline Patients requiring admission and antibiotic therapy & $18.2 \%$ & $78.6 \%$ \\
\hline Patients requiring no admission and antibiotic therapy & $54.5 \%$ & 12 days \\
\hline Average length of stay of operated patients. & 15.7 days & 6.5 days \\
\hline Average length of stay for non-operative patients. & 6.4 days & \\
\hline
\end{tabular}

Table 3: Acute diverticulitis is a very frequent pathology in the emergency setting. 
It is a disease that can range from mild to potentially severe, depending on which its treatment may vary. For a long time, antibiotic treatment has been the treatment of choice for mild acute diverticulitis; however, some studies have shown that dietary changes alone can resolve it $\mathrm{p}$ [8,9]. In our study, we can observe how the number of consultations of mild patients decreased without a very significant increase in the number of consultations of severe cases. We could deduce that a large percentage of patients with mild symptoms resolved without antibiotic treatment.

Another scenario that has occurred during this pandemic is the increase in the number of more severe patients, probably due to the delay in consulting the emergency department for fear of becoming infected by the coronavirus. As these are more severe forms of presentation, treatment has had to be more aggressive. The type of surgery performed during periods outside the pandemic has been less aggressive, such as abundant lavage of the abdominal cavity and drainage. However, sigmoidectomy type surgery with a terminal stoma (Hartmann Procedure) has gained prominence in this world pandemic. This surgery is performed in Hinchey III and IV patients [10,11]. There is data that links Hinchey III and IV patients up to an $8.7 \%$ mortality rate [10] but, in our center, the mortality rate has been $0 \%$, which leads us to believe that morbidity has not increased due to causes unrelated to the diverticular disease itself.

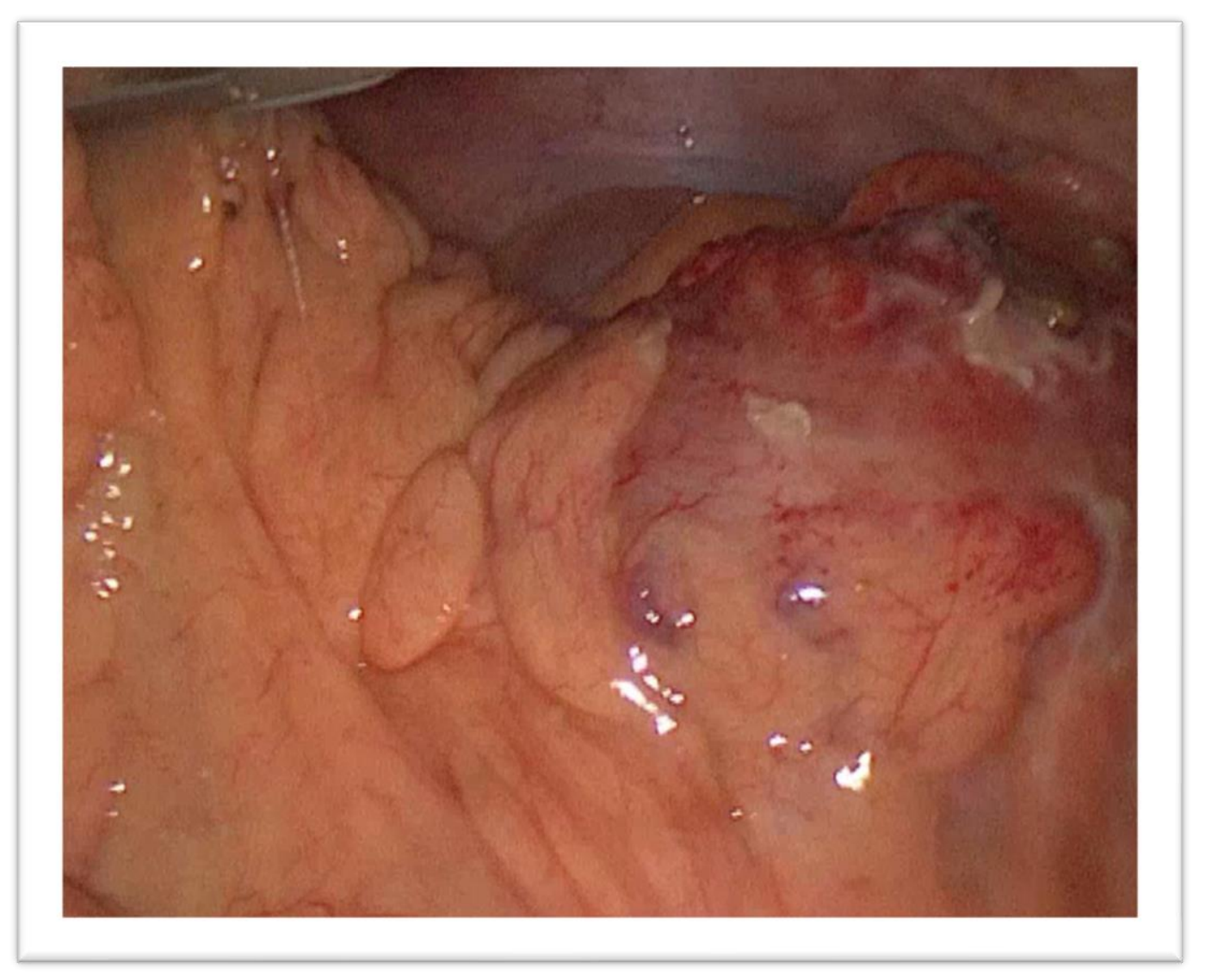

Figure 1. Acute Diverticulitis perforated

The hospital stays of patients requiring intravenous antibiotic treatment in the pandemic period were like that in 2019. As in the previous year, this was also not associated with a higher readmission rate nor did these patients end up requiring surgery. It has been seen in the literature that intravenous antibiotic is not associated with greater benefit compared with oral treatment, and the duration of treatment from 4 days to more than 7 days does not appear to have any advantage related to clinical outcomes $[11,12,13]$. It is likely that our patients admitted without the need for surgery would have had the same evolution if the treatment had been oral. In our center outside the pandemic period, we treat these patients in a protocolized manner. Thus, patients with uncomplicated diverticular disease (if they are under 75 years of age, not diabetic, or with a lot of associated comorbidity and family support) will be treated on an outpatient basis with antibiotic treatment and dietary restrictions. The rest of the patients who do not require surgical treatment, but are not candidates for outpatient treatment, are admitted for intravenous antibiotic treatment, in this way they are observed more closely, and in case of complication, early action could be taken.

\section{Conclusion}

The present study represents the trend and evolution of acute diverticulitis during the SARS-COV-2 pandemic. The incidence of acute diverticulitis was lower, although patients with higher severity (Hinchey III and IV) were registered. This situation probably caused surgical treatment to displace conservative treatment in these patients during the pandemic period. Conservative treatment (antibiotherapy and drainage) has been displaced by surgical treatment in this period

Likewise, no additional differences were observed due to COVID 19 disease. No case of mortality was reported in either period. 


\section{References}

1. Wheat CL, Strate LL (2016) Trends in Hospitalization for Diverticulitis and Diverticular Bleeding in the United States From 2000 to 2010. Clin Gastroenterol Hepatol. 14(1): 96-103 e1.

2. Bharucha AE, Parthasarathy G, Ditah I, Fletcher JG, Ewelukwa O, et al. (2015) Temporal Trends in the Incidence and Natural History of Diverticulitis: A Population-Based Study. Am J Gastroenterol. 110(11): 1589-96.

3. Schultz J, Azhar N, Binda G, Barbara G, Biondo S, et al. (2020) European Society of Coloproctology: guidelines for the management of diverticular disease of the colon. Colorectal Disease. 22(S2): 5-28.

4. Toru Tochigi, Chihiro Kosugi, Kiyohiko Shuto, Mikito Mori, Atsushi Hirano, et al. (2018) Management of complicated diverticulitis of the colon, Ann Gastroenterol Surg. 2(1): 22-27.

5. Coronavirus Outbreak. Available at: https://www.worldometers.info/coronavirus/. Accessed 23 Feb 2020.

6. Soriano V, Barreiro P (2020) Why such excess of mortality for COVID-19 in Spain? Ther Adv Infect Dis. 7: 2049936120932755.

7. López V, Vázquez T, Alonso-Titos J, Cabello M, Alonso A, et al. (2020) Recomendaciones en el manejo de la pandemia por coronavirus SARS-CoV-2 (Covid-19) en pacientes con trasplante renal. Nefrología. 40(3): 265-271.
8. Desai M, Fathallah J, Nutalapati V, Saligram S (2019) Antibiotics versus no antibiotics for acute uncomplicated diverticulitis: a systematic review and meta-analysis. Dis Colon Rectum 62(8): 1005-1012.

9. van Dijk ST, Chabok A, Dijkgraaf MG, Boermeester MA, Smedh K (2020) Observational versus antibiotic treatment for uncomplicated diverticulitis: an individual-patient data meta-analysis. Br J Surg 107(8): 1062-1069.

10. Gregersen R, Andresen K, Burcharth J, Pommergaard HC, Rosenberg J (2016) Short-term mortality, readmission, and recurrence in treatment of acute diverticulitis with abscess formation: a nationwide register-based cohort study. Int $\mathrm{J}$ Colorectal Dis 31(5): 983-990.

11. Biondo S, Golda T, Kreisler E, Espin E, Vallribera F, et al. (2014) Outpatients versus hospitalisation management for uncomplicated diverticulitis: a prospective, multicenter randomised clinical trial (DIVER Trial). Ann Surg 259(1): $38-44$.

12. Etzioni DA, Chiu VY, Cannom RR, Burchette RJ, Haigh PI, et al. (2010) Outpatient treatment of acute diverticulitis: rates and predictors of failure. Dis Colon Rectum 53(6): $861-865$.

13. Andeweg CS, Mulder IM, Felt-Bersma RJ, Verbon A, Wilt GJVD, et al. Guidelines of diagnostics and treatment of acute left-sided colonic diverticulitis. Dig Surg 30(4-6): 278-292. 